\title{
DISASTER MEDICINE IN SOUTH AFRICA
}

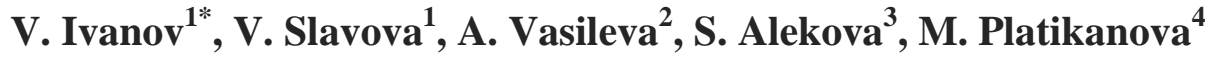 \\ ${ }^{1}$ Department of Neurology, Psychiatry and Medicine of the Disaster Situation, Medical Faculty, \\ Trakia University, Stara Zagora, Bulgaria \\ ${ }^{2}$ Student, Medical Faculty, Trakia University, Stara Zagora, Bulgaria \\ ${ }^{3}$ Department of General Medicine and Oftalmology, Medical Faculty, Trakia University, Stara Zagora, \\ Bulgaria \\ ${ }^{4}$ Department of Hygiene, Epidemiology and Infectious Diseases, Medical Faculty, Trakia University, \\ Stara Zagora, Bulgaria
}

\begin{abstract}
South Africa is the most economically developed country in Africa and among the twenty most developed in the world. The development of industry and particularly of certain risk sectors suggests an increased risk of anthropogenic catastrophes. The leading economical sector is the extraction of minerals. South Africa is on the first place in the world, concerning the production of gold, platinum, chromium and manganese. Key positions held and diamond mining (on the first place for the production's value), coal (mainly black), uranium and asbestos. Other significant inputs are vanadium, iron-ore, lead, titanium, graphite, silver and copper - ore. The development of underground minerals is fraught with dangers. It is therefore inevitable to occur accidents in the mines. Recently by the frequency of spontaneous and natural disasters has increased. Hence, there appears the need of timely and efficient planning, management and organization of the preventive activities, and the events for the medical insurance of the population in time of disasters.

The purpose of this report is to provide some data and to share personal observations on the level of disaster medicine in South Africa.
\end{abstract}

Key words: disaster protection, disaster situation, medical preparedness

\section{INTRODUCTION}

The Republic of South Africa is economically the best developed country in Africa and among the ten best economies in the world (1). The country contributes $40 \%$ to the total industrial production on the continent (2).

The leading branch of the economy of South Africa natural resource extraction. The Republic of South Africa is the world market leader in gold, platinum, chromium and manganese extraction. The country also takes a leading position in industrial yielding of diamonds (highest cost of total production), coal (mainly black coal), uranium and asbestos (1). Other resources of industrial importance are vanadium, iron ore, lead, titanium, graphite, silver and copper ore.

Industrial extraction of natural resources is a risky process and in some cases underground

\footnotetext{
*Correspondence to: Veselin Ivanov, E-mail: veskoasenov@abv.bg,Tel: +359042664332
}

mine accidents are inevitable (3). Over the last few years the incidence of natural disasters has also increased. It all calls for timely and efficient prevention planning and risk management, as well as providing efficient medical response in such cases.

An important element of industrial risk management and prevention is providing medical staff with sufficient information about the harmful effects different accidents and disasters can cause and the impact they can have on human beings exposed to such effects. Prior preparation and training concerning reaction behaviour and actions that should be taken in cases of natural disasters or accidents is a guarantee for effective and timely organisation and proper management of medical reaction and proper protection of the population affected.

\section{PURPOSE}

The purpose of the study is to investigate the level of organisation and medical training the 
university programme of Disaster Medicine provides in the Republic of South Africa and to share personal experience and observation concerning the country's preparedness for disaster response.

\section{MATERIAL AND METHODS}

Descriptive analysis of scientific publications on the subject of specific education and training of medical students and the citizens of South Africa concerning disaster response organisation and medical care provision. Observation and study on the disaster response preparedness at the University of Johannesburg, carried out by one of the authors of the current publication. The visit was carried out in the period November 2014 January 2015.

\section{RESULTS AND DISCUSSION}

The necessity of establishing a holistic, multilateral approach to organising disaster response in order to minimise the disaster impact has become ever more obvious. To that end, in South Africa a great priority is given to disaster management by educating and training fully-fledged professionals in the field. With a view to improving the regional, national and continental disaster management capacity and in support to the National Law on Natural and Man-made Disaster Management, the University of Johannesburg, South Africa has developed a Master's Degree on Disaster Management, as a subdivision of Public Health Management (4). The aim of the programme is to educate and train specialists in medical care and other related areas to act as public health managers, disaster impact on human health assessors and disaster response coordinators in cases of accidents and natural disasters.

In 2010 the Republic of South Africa hosted the FIFA World Cup Championship, an event that attracted masses of people to the hosting cities of South Africa, making them vulnerable to accidents and disasters (5). As a prevention measure, the South African Health Care Ministry appointed a body of experts to assess the preparedness of public hospitals in the regions to properly respond in cases of accidents and disasters, to identify the best practices, as well as the most common problems and to make recommendations for improving those hospitals' preparedness for disaster response (6). After analysing available data the body of experts issued a seven-point list of specific recommendations.

The Johannesburg University library has a rich fund of accident and disaster medicine literature (Picture 1). On the university campus there are special disaster rooms
(Picture 2), storing all necessary technical support and materials to be used in cases of accidents and disasters. Fire plugs and insulation gas masks are placed in specific places on campus, providing free access to them in case of accidents (Picture 3 and 4).

Unlike in the Republic of South Africa, in Bulgaria the common practice is not to place a gas mask next to the fire plugs (fire extinguishers) in buildings, which to be used by the person rescuing other people in danger, which also violates the regulations of the Law on Disaster Protection from 2006. (Article 34. Any natural person shall be held responsible for helping another human being, whose life or health is endangered as a result of an accident or disaster, given that their own life or health are not in danger;) (7).

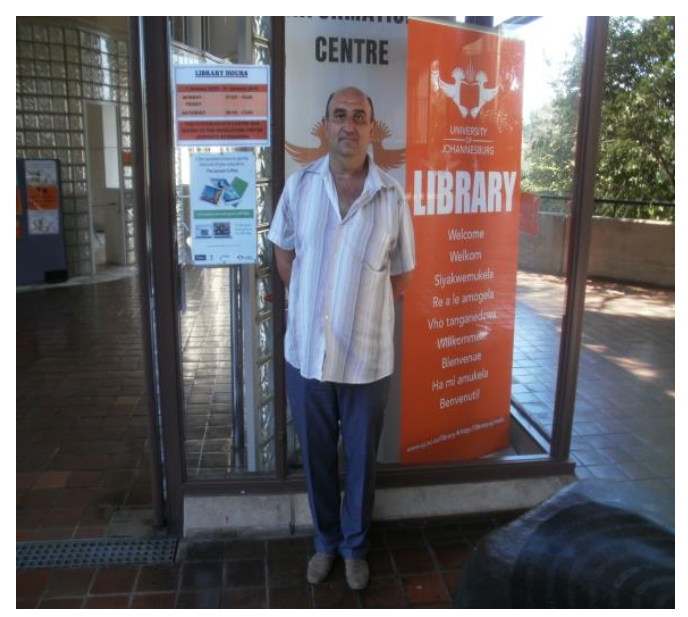

Picture 1.

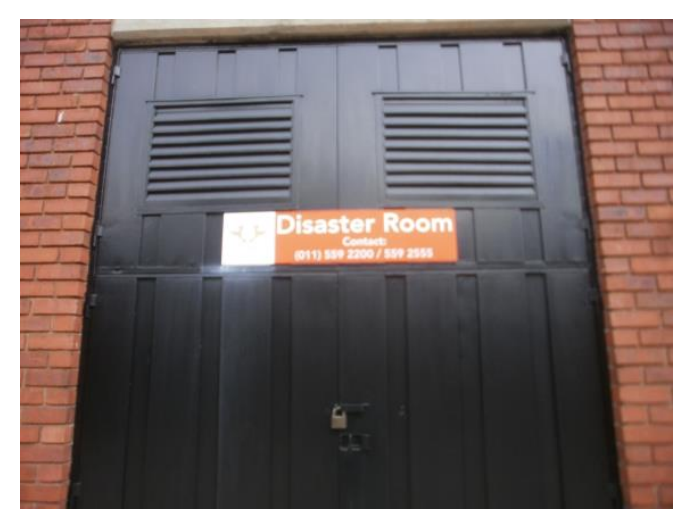

Picture 2.

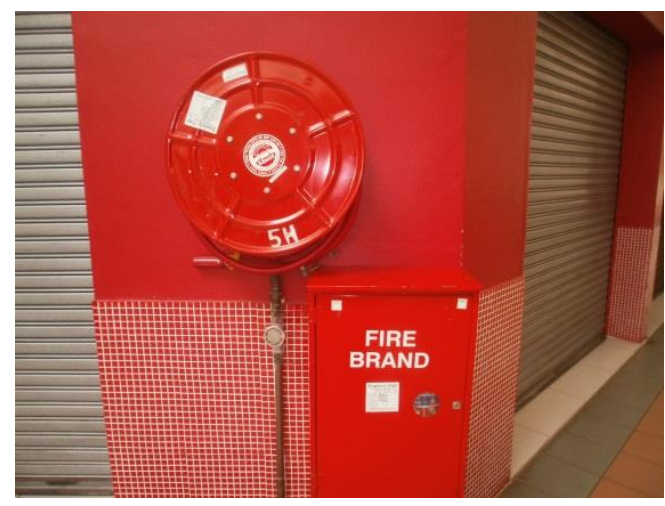

Picture 3. 


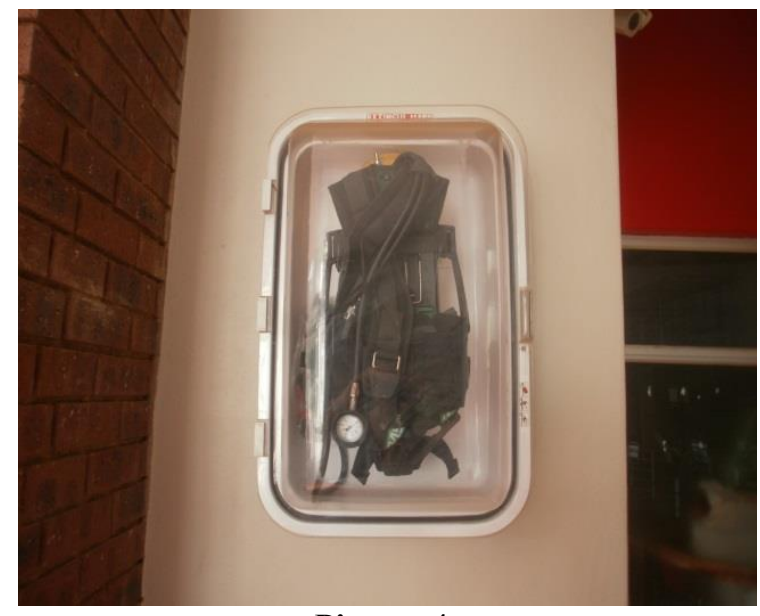

Picture 4.

In all dormitory rooms (Picture 5), laboratories, lecture halls and in the canteen (Picture 6) there are clearly visible information boards, providing step-by-step instructions about how to behave and what actions to take in cases of accidents and disasters. They also contain a reliable contact telephone number to be used in cases of necessity. There are large, easily noticeable signs, showing the shortest way of evacuation and to evacuation meeting points (Picture 7), as well as where the meeting points are depending on where you happen to be, in different parts of the building or on campus (Picture 8).

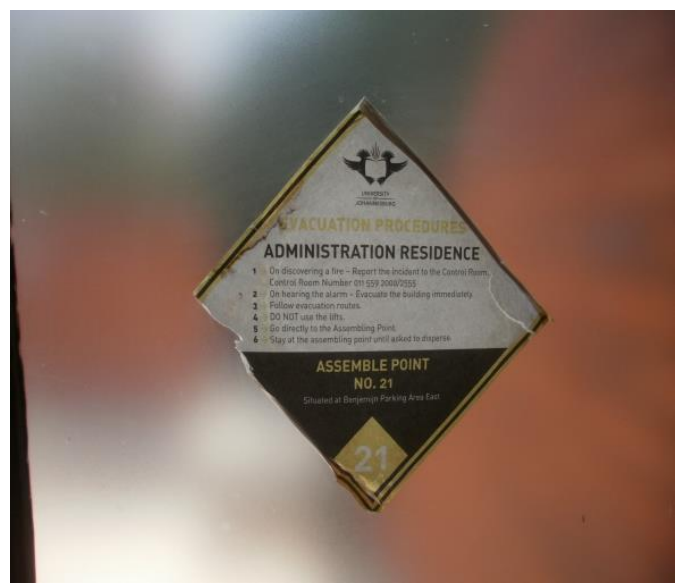

Picture 5.
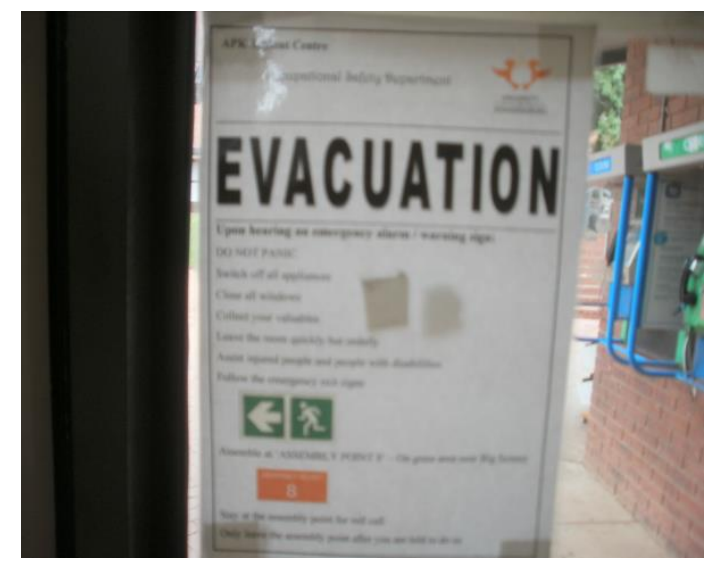

Picture 6.

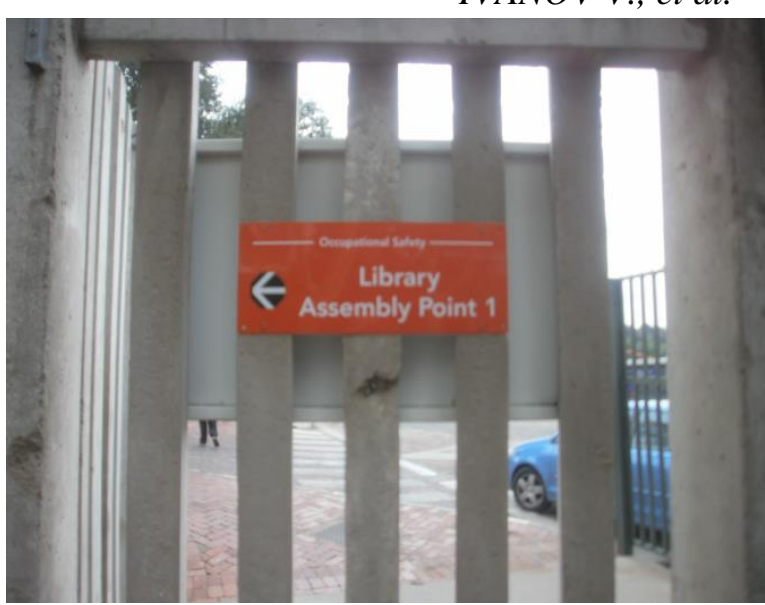

Picture 7.

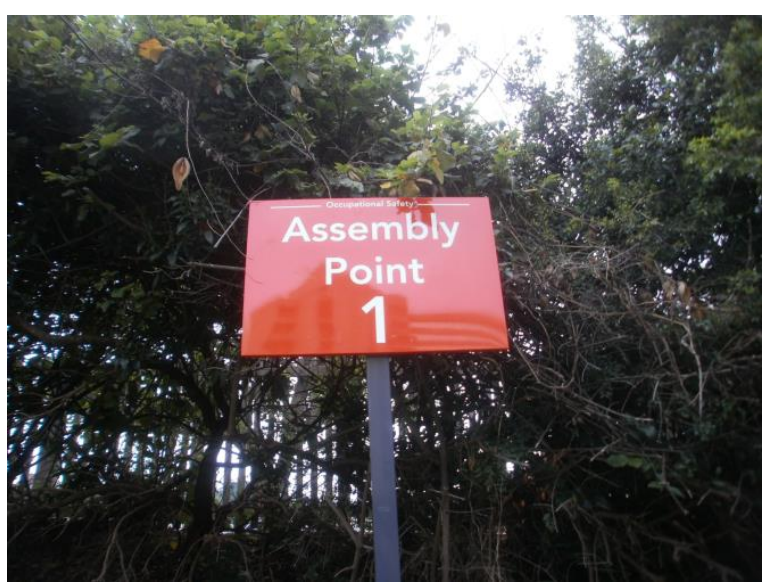

Picture 8.

\section{CONCLUSIONS}

In the Republic of South Africa not only is the risk of natural disasters high but so is the risk of man-made accidents and disasters. A key priority in their human impact prevention measures is given to providing medical students with specific education and training concerning their preparedness for reaction in cases of accidents and disasters. They have also created a well-developed disaster response organisation aiming at diminishing the number of possible victims and the human impact of natural and man-made disasters.

\section{ACKNOWLEDGEMENTS}

This research has been supported in part through European Community via Marie Curie International Research Staff Exchange Scheme under 7th framework(PIRSES-GA-2012316067) and Scientific project №7/2013 of MF, Trakia University.

\section{REFERENCES}

1. Doykov, V. and others. Economic geography of countries from the continents of Asia, America, Africa, Australia, Antarctica. Kovachev, 2008. ISBN 978954-8775-88-5.

2. Lukanov, A. and others. Countries in the world 2002 - guide. Sofia, Gloria Palace, 2002. ISBN 954-90833-2-2. 
3. Oosthuizen H. Mining disasters in South Africa: the Rovic Diamond Mine disaster and the criminal liability of the mine authorities. Med Law. 2003;22(1):11-28.

4. Macfarlane C, Joffe AL, Naidoo S. Training of disaster managers at a masters degree level: from emergency care to managerial control. Emerg Med Australas. 2006 Oct-Dec;18(5-6):451-6.

5. Valesky W, Roblin P, Patel B, Adelaine J, Zehtabchi S, Arquilla B. Assessing hospital preparedness: comparison of an on-site survey with a self-reported, internet-based, long-distance tabletop drill. Prehosp Disaster Med. 2013 Oct;28(5):4414. doi: 10.1017/S1049023X13003580. Epub 2013 May 21.

6. Stander M, Wallis LA, Smith WP. Hospital disaster planning in the Western cape, South Africa. Prehosp Disaster Med. 2011 Jul-Aug;26(4):283-8. doi: 10.1017/S1049023X11006571. Epub 2011 Oct 7.

7. Romanova Ch. Protection and medical assistance in emergency situations, Varna, Colour Print, 2012, p. 117. 